\title{
Sonographic measurement of lung aeration versus rapid shallow breathing index as a predictor of successful weaning from mechanical ventilation \\ Nabila I. Laz ${ }^{\mathrm{a}}$, Mohammad F. Mohammad ${ }^{\mathrm{a}}$, Sahar M. Abdelsalam ${ }^{\mathrm{b}}$, Radwa M. Abdelwahab ${ }^{\mathrm{c}}$
}

\begin{abstract}
Background Lung ultrasonography is a beneficial tool for evaluation of the extent of lung aeration through measurement of the amount of extravascular lung water. Lung ultrasonography offers some advantages over other methods of assessment of lung aeration including the lack of ionizing radiation and the possibility of use at patient's bedside. It facilitates dynamic assessment of the lung during mechanical ventilation and during weaning.
\end{abstract}

Aim To assess lung aeration by lung ultrasonography in patients ready for weaning and to validate the significance of its use as a predictor of weaning outcome in comparison with rapid shallow breathing index.

Patients and methods A prospective observational study was conducted on 30 critically ill mechanically ventilated patients for $48 \mathrm{~h}$ or more, and ready to undergo spontaneous breathing trial (SBT), according to the readiness criteria. It was conducted in Beni-Suef University Hospital from October 2017 to May 2018. Rapid shallow breathing index was measured before initiation of SBT, and lung ultrasound was done, before, during, and after SBT [lung ultrasound score (LUS) 1, 2, and 3] and were used as predictors for SBT outcome. Patients were divided, according to outcome, into successful weaning group (group A) and failed weaning group (group B).

\section{Introduction}

Mechanical ventilation is significant as a life-saving intervention in any sort of respiratory failure. It is a crude intervention that is only used in critically ill patients in life-threatening conditions [1]. Pulmonary complications of mechanical ventilation increase in incidence with the duration of ventilation, so early successful weaning is a cornerstone in prevention of these complications $[2,3]$. Weaning failure is a major problem that is commonly seen in critically ill patients. Weaning failure includes spontaneous breathing trial (SBT) failure [4] and postextubation distress that requires re-intubation or noninvasive ventilation within $48 \mathrm{~h}$ after extubation [5]. Assessment of readiness of weaning and the ideal time for extubation play an important role in determination of predicted hospital stay and prediction of outcome [2]. Many mechanisms are incriminated in weaning failure from mechanical ventilation, for example, alteration of lung resistance or compliance during weaning process, lung derecruitement, spontaneous breathing-induced cardiac dysfunction, and neuromuscular disorders. Most of these factors are associated with decreased lung aeration
Results In the failed weaning group, LUS1, LUS2, and LUS3 were significantly higher than those of the successful weaning group. At cutoff value of 8.5 , LUS3 could be used for prediction of weaning failure with sensitivity $85 \%$ and specificity $100 \%$. Moreover, there was a statistically significant relation between LUS and the other variables including hospital stay, mechanical ventilation duration, and mortality.

Conclusion Lung ultrasound is useful as a bedside tool that can help physicians in their weaning decisions.

Egypt J Bronchol 2019 13:477-483

(C) 2019 Egyptian Journal of Bronchology

Egyptian Journal of Bronchology 2019 13:477-483

Keywords: extravascular lung water, lung ultrasound score, rapid shallow breathing index, spontaneous breathing trial

Departments of, achest, ${ }^{b}$ Radiology, Faculty of Medicine, Beni-Suef University, 'Department of Chest, Beni-Suef Chest Hospital, Beni-Suef, Egypt

Correspondence to Radwa M. Abdelwahab, MSc, Department of Chest Beni-Suef Chest Hospital, Beni-Suef 62611, Egypt. Tel: +20 111911 3563; e-mail: radwa10911@yahoo.com

Received: 15 January 2019 Revised: 26 March 2019 Accepted: 14 July 2019 Published: 25 October 2019

during SBT and lead to weaning failure [6]. Derecruitement, which could be a possible cause of weaning failure, needs to be directly studied to predict and early diagnose failure of the weaning process [7]. Different variables are used as predictors of weaning; the rapid shallow breathing index (RSBI) is the most widely used predictor of weaning success [8]. Visualization of the lungs was not possible by ultrasound for a long time. However, nowadays we can use the artefacts produced at the interface between the lungs and other substances, for example, fluids, to identify specific pathologies in the lung [9]. Lung ultrasound could be used as a predictor of weaning failure by detection of lung aeration loss before weaning and during the SBT [10]. Being a bedside, noninvasive, radiation free, quickly performed procedure and able to perform a dynamic assessment of changes of lung aeration makes it superior to other procedures that

This is an open access journal, and articles are distributed under the terms of the Creative Commons Attribution-NonCommercial-ShareAlike 4.0 License, which allows others to remix, tweak, and build upon the work non-commercially, as long as appropriate credit is given and the new creations are licensed under the identical terms. 
can be used to assess lung aeration and to predict success of weaning process, so it needs further research and studies to prove its efficacy and accuracy [11].

\section{Patients and methods}

Thirty critically ill ventilated patients admitted to Beni-Suef University Hospital from October 2017 to May 2018 were enrolled in the study. The study protocol was approved by the research ethical committee of Beni-Suef University. A written consent was taken from the patients' close relatives for agreement of enrollment in the study.

\section{Inclusion criteria}

Patients invasively ventilated for $48 \mathrm{~h}$ or more and ready to undergo a SBT according to the traditional readiness criteria were included [12].

\section{Exclusion criteria}

Patients less than 18 years old; patients with traumatic lung injury or pneumothorax; patients with interstitial lung disease, bullous lung lesion, or extensive bronchiectasis; patients with chest wall lesion that impairs the use of chest ultrasound, for example, burn and open wound; morbid obese patients with BMI of at least $40 \mathrm{~kg} / \mathrm{m}^{2}$; and patients with a previously failed SBT were excluded.

\section{Study design}

RSBI was measured, and lung ultrasonography was done just before initiation of SBT [lung ultrasound score (LUS) 1]. Included patients were then subjected to an SBT using (PSV) with pressure support less than or equal to $10 \mathrm{cmH}_{2} \mathrm{O}$ and PEEP up to $5 \mathrm{cmH}_{2} \mathrm{O}$. During this phase, clinical, laboratory, $\mathrm{ABG}$, and ventilator data were recorded. Lung ultrasonography was done at the end of SBT (LUS2) [1]. According to weaning outcome, patients were divided into two groups: successful weaning group (group A), which included patients who successfully passed an SBT and were weaned from mechanical ventilation with no need for re-intubation or noninvasive ventilation in the subsequent $48 \mathrm{~h}$, and failed weaning group (group B), which included patients who failed during SBT and were brought back to assist ventilation and patients who required re-intubation or noninvasive ventilation within $48 \mathrm{~h}$ after extubation. Lung ultrasonography was done 4-6h after extubation (LUS3), and patients were observed for $48 \mathrm{~h}$ to assess the need of re-intubation or noninvasive ventilation, indicating failed weaning. In group B patients, LUS3 was done on failure of the weaning process or just after reinstitution of mechanical ventilation.

\section{Study outcomes}

The primary outcome measures were respiratory distress requiring reintubation or noninvasive ventilation within $48 \mathrm{~h}$ after weaning.

The secondary outcome measures were hospital mortality and length of ICU stay within 28 days.

\section{Methods}

Lung ultrasonography was done using LOGIC PRO 100 (KPI Health care company, India) and EDAN DUS 60 (Global health company, China) ultrasound devices by applying B-Mode, with the use of a convex probe $(5.5 \mathrm{MHz})$. The probe was applied vertically over the examined intercostal spaces in each region, with the patients lying flat or in the semi-recumbent position. Lung ultrasonography was done before, during, and after SBT. Lung ultrasound was used to assess the degree of lung aeration loss according to LUS score [13], according to which the chest wall is divided into 12 zones (six zones per side). Each hemithorax is divided into three zones by the parasternal line, anterior axillary line (AAL), posterior axillary line (PAL) and the paravertebral line, and then each zone is divided into upper and lower zones, above and below fifth intercostal space [13]. One of four patterns of aeration was recognized for each region (Table 1 and Fig. 1).

\section{Statistical analysis}

The software used in analysis was the version 15 of the statistical package SPSS (self-propelled semisubmersible, Microsoft, USA). Mean and SD values were compared using simple $t$-test. Pearson's correlation test was used to study the association between each two variables among each group for numerical data. The probability of error $(P$ value) up to 0.05 was considered significant. Receiver operating characteristic (ROC) curve analysis was done to predict the cutoff points of the test variables (RSBI, LUS1, LUS2, and LUS3) that best predict the binary state of another variable.

Table 1 Lung aeration patterns as detected during lung ultrasonography

\begin{tabular}{lcc}
\hline $\begin{array}{l}\text { Aeration } \\
\text { pattern }\end{array}$ & Score & Description \\
\hline $\begin{array}{l}\text { Normal } \\
\text { Moderate }\end{array}$ & 0 & $\begin{array}{c}\text { Lung sliding, A lines, and } \leq 3 \text { B lines } \\
\text { Multiple regularly and irregularly spaced } \\
\text { loss lines }\end{array}$ \\
$\begin{array}{l}\text { Severe loss } \\
\text { Complete }\end{array}$ & 2 & Multiple and coalescent B lines \\
loss & 3 & Lung consolidation \\
\hline
\end{tabular}


Figure 1

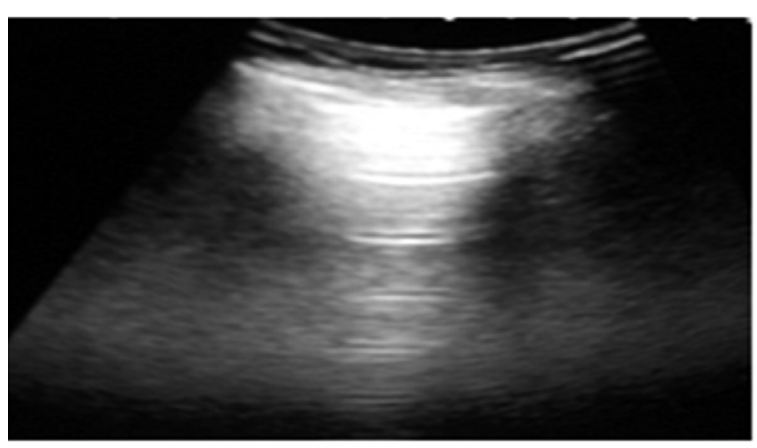

Normal

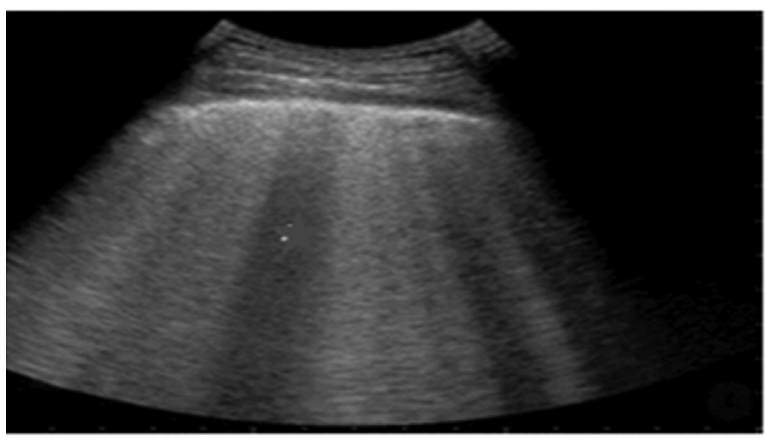

Severe loss of aeration

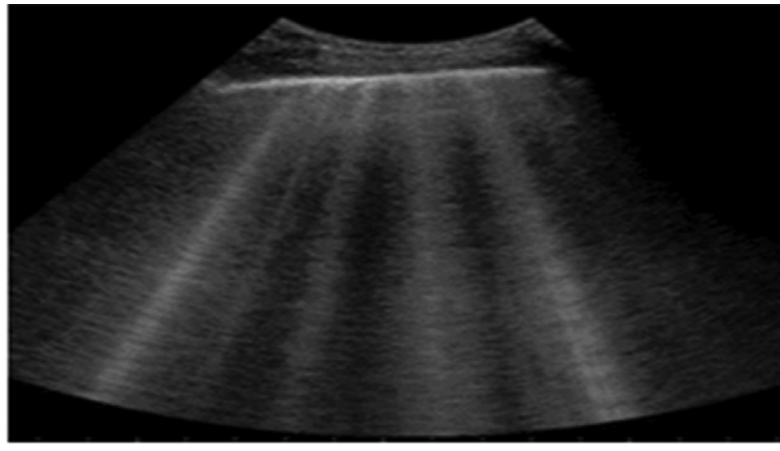

Moderate loss of aeration

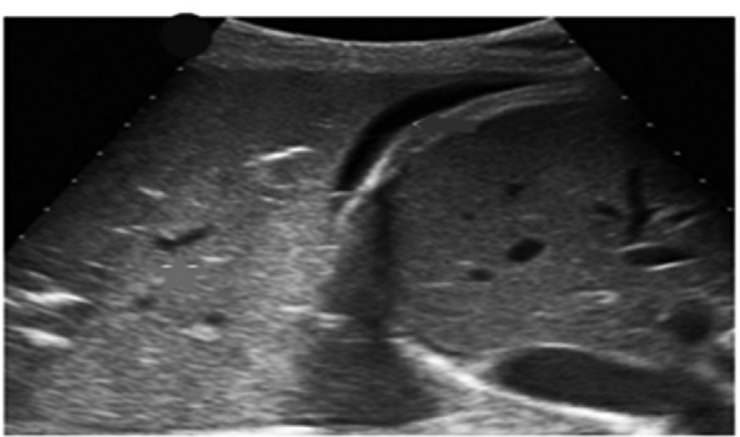

Consolidation

Lung aeration patterns detected by lung ultrasonography.

Figure 2

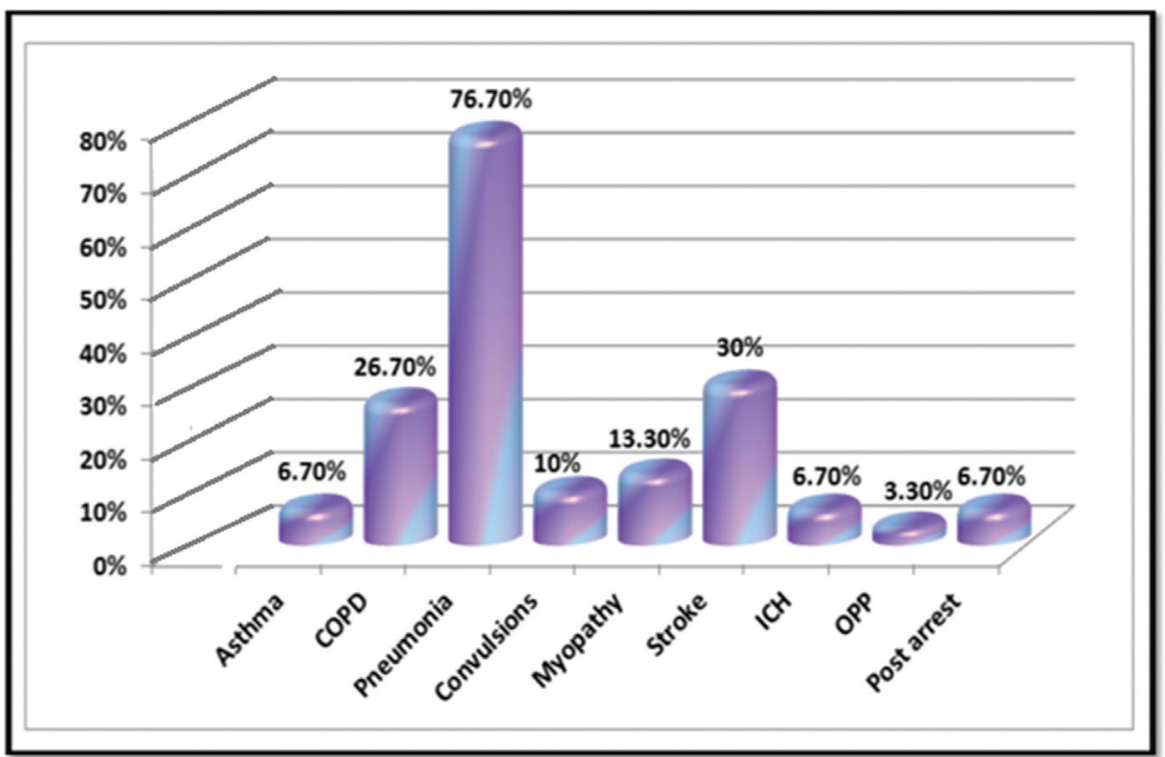

Risk factors of the included patients.

\section{Results}

The study included 30 patients; the age of the studied patients ranged from 19 to 84 years, with a median age of 66.5 years and mean $\pm \mathrm{SD}$ was $60.8 \pm 20.1$ years. Of the studied patients, 18 (60\%) were males and 12 (40\%) were females. Included patients had multiple risk factors and comorbidities; $76.7 \%$ had pneumonia, and 50\% were hypertensive. Risk factors and comorbidities of included patients are presented in Figs 2 and 3 [2].

Length of hospital stay ranged from 3 to 28 days, with mean $\pm \mathrm{SD}$ of $16.1 \pm 8.3$ days. Ventilation days of included patients ranged from 2 to 25 days, with 


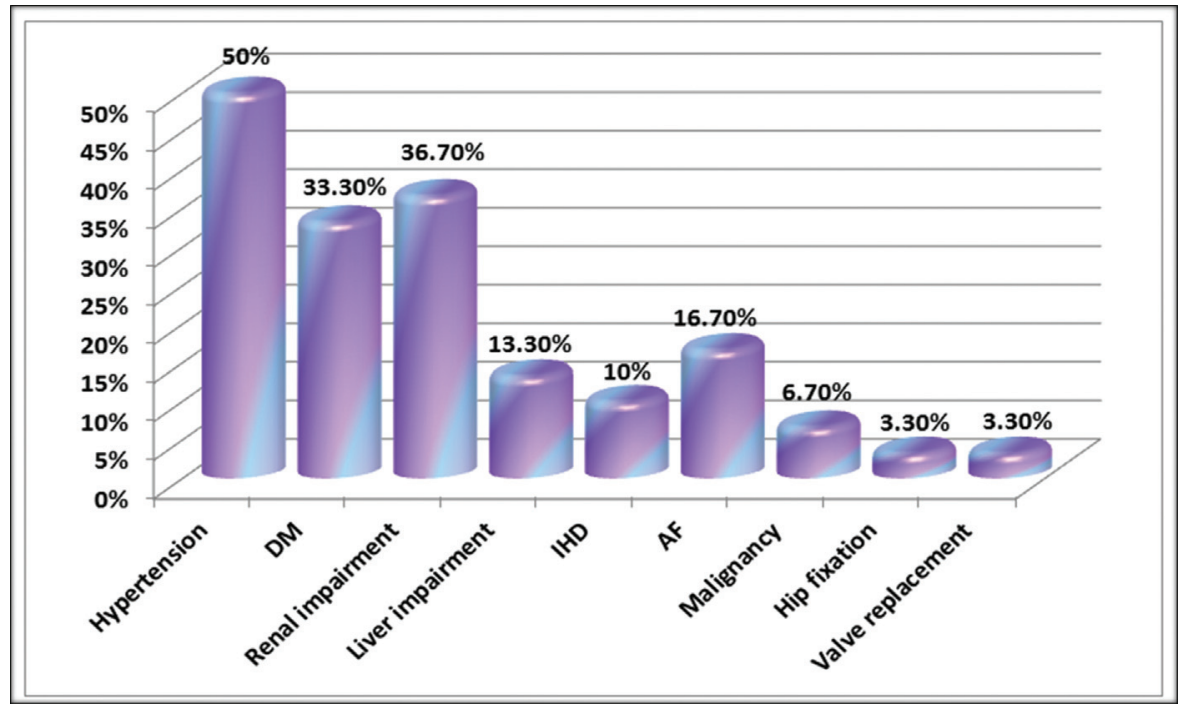

Comorbidities of the included patients.

mean $\pm \mathrm{SD}$ of $9.7 \pm 6.6$ days. Of the included patients, 10 (33.3\%) were successfully weaned; however, the remaining 20 (66.7\%) were classified as failed weaning patients owing to either failure of SBT or owing to the need of re-ventilation within $48 \mathrm{~h}$ after weaning. Of the included patients, 16 (53.3\%) were survivors, whereas $14(46.7 \%)$ patients were nonsurvivors. Demographic data and clinical criteria of the included patients are described in Table 2.

Statistical results of included patients were correlated with the study outcomes; a statistically significant difference was found between mean pressure of arterial oxygen $\left(\mathrm{PaO}_{2}\right) /$ fraction of inspired oxygen ratio for patients who failed weaning $(213 \pm 70)$ and that for who were successfully weaned $(306.2 \pm 128.3)$, with $P$ value 0.015 . Moreover, a statistically significant difference was found between mean LUS1, LUS2, and LUS3 for patients who failed to be weaned and that for who were successfully weaned, with $P$ value less than 0.05 . Correlative data between different variables and study outcomes are illustrated in Tables 3-5.

Receiver operator characteristic curves were used to test the LUS1, LUS2, and LUS3 and RSBI as predictors of failure of weaning from mechanical ventilation. The positive actual state is failed weaning (Table 6 and Fig. 4). ROC curve illustrates the potential of RSBI, LUS1, LUS2, and LUS3 as predictors of weaning failure as follows: At a cutoff value of 34.5 (25-94) the sensitivity of RSBI was $80 \%$ and the specificity was $30 \%$ [area under the curve (AUC) $=0.590$ ), positive predictive value $(\mathrm{PPV})=69.6 \%$, and negative predictive value $(\mathrm{NPV})=42.8 \%]$. At a cutoff value of 11.5
Table 2 Demographic data and clinical criteria of the included patients

\begin{tabular}{lcc}
\hline Item & Range/N $(\%)$ & Mean \pm SD \\
\hline Age & $19-48$ & $60.8 \pm 20.1$ \\
Sex & & \\
$\quad$ Male & $18(60)$ & \\
$\quad$ Female & $12(40)$ & \\
GCS & $10-15$ & $14.1 \pm 1.58$ \\
MAP & $55-78$ & $66.6 \pm 6.7$ \\
RR & $12-30$ & $20.7 \pm 5.9$ \\
Temperature & $36.5-39.5$ & $37.5 \pm 0.9$ \\
Pulse & $61-102$ & $83.1 \pm 11.9$ \\
BMI & $20-40$ & $31.03 \pm 4.9$ \\
PaO ${ }_{2} /$ FiO & \\
Peak pressure & $150-570$ & $244.2 \pm 101.5$ \\
Plateau pressure & $19.1-38$ & $25.5 \pm 4.4$ \\
Mean airway pressure & $11-28$ & $17.3 \pm 4.6$ \\
Static compliance & $4-23$ & $10.07 \pm 3.2$ \\
Ventilator days & $20.2-62.1$ & $39.8 \pm 13.2$ \\
Length of ICU stay & $2-25$ & $9.7 \pm 6.6$ \\
Failed weaning & $3-28$ & $16.1 \pm 8.3$ \\
Successful weaning & $20(66.7)$ & \\
Survivors & $10(33.3)$ & \\
Nonsurvivors & $16(53.3)$ & \\
\hline
\end{tabular}

$\mathrm{FiO}_{2}$, fraction of inspired oxygen; GCS, Glasgow coma scale; MAP, mean arterial pressure; $\mathrm{PaO}_{2}$, pressure of arterial oxygen; $\mathrm{RR}$, respiratory rate.

(1.5-20), the sensitivity of LUS1 was $90 \%$ and the specificity was $50 \%$ (AUC $=0.773, \mathrm{PPV}=78.3 \%$, and $\mathrm{NPV}=71.4 \%)$. At a cutoff value of $8.5(0.5-18.5)$, the sensitivity of LUS2 was $80 \%$ and the specificity was $70 \%(\mathrm{AUC}=0.830, \mathrm{PPV}=84.2 \%$, and $\mathrm{NPV}=63.6 \%$ ). At a cutoff value of 8.5 (2-21), the sensitivity of LUS3 was $85 \%$ and the specificity was $100 \%$ (AUC $=0.903$, $\mathrm{PPV}=100 \%$, and $\mathrm{NPV}=76.9 \%$ ). 
Table 3 Correlative data between successful and failed weaning groups

\begin{tabular}{|c|c|c|c|}
\hline Item & $\begin{array}{c}\text { Failed } \\
\text { weaning }\end{array}$ & $\begin{array}{l}\text { Successful } \\
\text { weaning }\end{array}$ & $\begin{array}{c}P \\
\text { value }\end{array}$ \\
\hline Age (years) & $62 \pm 18.7$ & $58.3 \pm 23.3$ & 0.854 \\
\hline \multicolumn{4}{|l|}{ Sex } \\
\hline Female & $8(40)$ & $4(40)$ & 0.456 \\
\hline Male & $12(60)$ & $6(60)$ & \\
\hline GCS & $14 \pm 1.7$ & $14.3 \pm 1.2$ & 0.457 \\
\hline MAP & $59.6 \pm 2.3$ & $71.9 \pm 6.1$ & 0.564 \\
\hline $\mathrm{RR}$ & $27.6 \pm 2.3$ & $22.6 \pm 2.3$ & 0.745 \\
\hline Temperature & $37.8 \pm 0.6$ & $37.8 \pm 0.3$ & 0.986 \\
\hline Pulse & $92.4 \pm 3.2$ & $85.1 \pm 11.6$ & 0.365 \\
\hline BMI & $30.1 \pm 3.1$ & $33 \pm 7$ & 0.765 \\
\hline $\mathrm{PaO}_{2} / \mathrm{FiO}_{2}$ & $213.3 \pm 70$ & $306.2 \pm 128.3$ & 0.015 \\
\hline $\mathrm{RSBI}$ & $57.8 \pm 23.65$ & $49.8 \pm 18.2$ & 0.390 \\
\hline LUS1 & $14.3 \pm 5.3$ & $10.2 \pm 4.4$ & 0.044 \\
\hline LUS2 & $10.7 \pm 4.8$ & $6.3 \pm 2.7$ & 0.012 \\
\hline LUS3 & $13.5 \pm 5.5$ & $5.7 \pm 2.1$ & $<0.001$ \\
\hline $\begin{array}{l}\text { Duration of } \\
\text { ventilation }\end{array}$ & $12.7 \pm 6$ & $3.7 \pm 2.4$ & $<0.001$ \\
\hline Length of ICU stay & $19.7 \pm 7.1$ & $8.9 \pm 5.2$ & $<0.001$ \\
\hline
\end{tabular}

$\mathrm{FiO}_{2}$, fraction of inspired oxygen; GCS, Glasgow coma scale; LUS1, lung ultrasound score during positive pressure ventilation; LUS2, lung ultrasound score during spontaneous breathing trial; LUS3, lung ultrasound score after weaning from mechanical ventilation; MAP, mean arterial pressure; $\mathrm{PaO}_{2}$, pressure of arterial oxygen; $\mathrm{RR}$, respiratory rate; $\mathrm{RSBI}$, rapid shallow breathing index.

Table 4 Correlative data between survivors and nonsurvivors

\begin{tabular}{lccc}
\hline Items & Survivors & Nonsurvivors & $P$ value \\
\hline Duration of ventilation & $9.1 \pm 7.9$ & $10.2 \pm 4.9$ & 0.545 \\
Length of ICU stay & $15.5 \pm 9.8$ & $16.8 \pm 6.3$ & 0.634 \\
LUS1 & $11.25 \pm 5.25$ & $14.85 \pm 4.81$ & 0.061 \\
LUS2 & $7.87 \pm 5.14$ & $10.86 \pm 3.65$ & 0.082 \\
LUS3 & $8.06 \pm 5.09$ & $14.14 \pm 5.28$ & 0.003 \\
\hline
\end{tabular}

LUS1, lung ultrasound score during positive pressure ventilation; LUS2, lung ultrasound score during spontaneous breathing trial; LUS3, lung ultrasound score after weaning from mechanical ventilation.

\section{Discussion}

Chest ultrasound is a quick bedside test and a noninvasive reliable technique for the assessment of pulmonary congestion [14]. This study hypothesis was built on the assumption that LUS can accurately detect extravascular lung water and quantify for the degree of aeration loss. Hence, it can be used to detect SBTassociated lung derecruitement and can significantly predict the results of weaning before and during initiation of the weaning process. This study showed a statistically significant difference between mean $\mathrm{PaO}_{2} /$ fraction of inspired oxygen ratio of patients who failed to be weaned and that of who were successfully weaned, with $P$ value 0.015 . Similar to these results, Osman and Hashim [15] stated that the mean value $\mathrm{PaO}_{2}$ was higher in the successful weaning
Table 5 Correlation between lung ultrasound score during spontaneous breathing trial and length of ICU stay

\begin{tabular}{lc}
\hline Length of ICU stay & LUS2 \\
\hline Pearson correlation $(r)$ & 0.364 \\
$P$ value & 0.048 \\
\hline LUS2 lung ultrasound score during spontaneous breathing trial
\end{tabular}

LUS2, lung ultrasound score during spontaneous breathing trial.

Table 6 ROC curve analysis for lung ultrasound score 1, 2, 3 and rapid shallow breathing index in relation to weaning success

\begin{tabular}{lcccc}
\hline & RSBI & LUS1 & LUS2 & LUS3 \\
\hline Cutoff point & 34.5 & 11.5 & 8.5 & 8.5 \\
Low probability of failure & $<25$ & $<1.5$ & $<0.5$ & $<2$ \\
Intermediate probability of & $25-94$ & $1.5-20$ & $0.5-18.5$ & $2-21$ \\
failure & & & & \\
High probability of failure & $>94$ & $>20$ & $>18.5$ & $>21$ \\
Sensitivity (\%) & 80 & 90 & 80 & 85 \\
Specificity (\%) & 30 & 50 & 70 & 100 \\
PPV (\%) & 69.6 & 78.3 & 84.2 & 100 \\
NPV (\%) & 42.8 & 71.4 & 63.6 & 76.9 \\
AUC & 0.590 & 0.773 & 0.830 & 0.903 \\
\hline
\end{tabular}

AUC, area under the curve; LUS1, lung ultrasound score during positive pressure ventilation; LUS2, lung ultrasound score during spontaneous breathing trial; LUS3, lung ultrasound score after weaning from mechanical ventilation; NPV, negative predictive value; PPV, positive predictive value; ROC, receiver operating characteristic; RSBI, rapid shallow breathing index.

group than the failed weaning group, with mean values of 69.7 and 46.6, respectively, which was considered statistically significant.

This study could not find a statistically significant difference between failure and successful weaning groups regarding any of the clinical and laboratory data. Similarly, Tenza-Lozano et al. [16] performed a prospective cohort study including patients ventilated for more than $24 \mathrm{~h}$ and ready to be weaned. No significant relation between hemodynamic monitoring and study outcomes could be detected. Against these results, Haji et al. [17] found that there was a significant increase in the respiratory rate for those who failed weaning than those who succeeded, with $P$ value of 0.02 . This difference from this study can be explained by single measurement of the hemodynamic parameters at initiation of the SBT and were not followed after success or failure of SBT. Moreover, in this study, respiratory rate was estimated on pressure support ventilation not on $\mathrm{T}$-piece.

This study did not find any significant statistical difference in mean values of RSBI between successful weaning group and failed weaning group. Similarly, Tenza-Lozano et al. [16] could not detect a statistical significance in the difference of mean values 


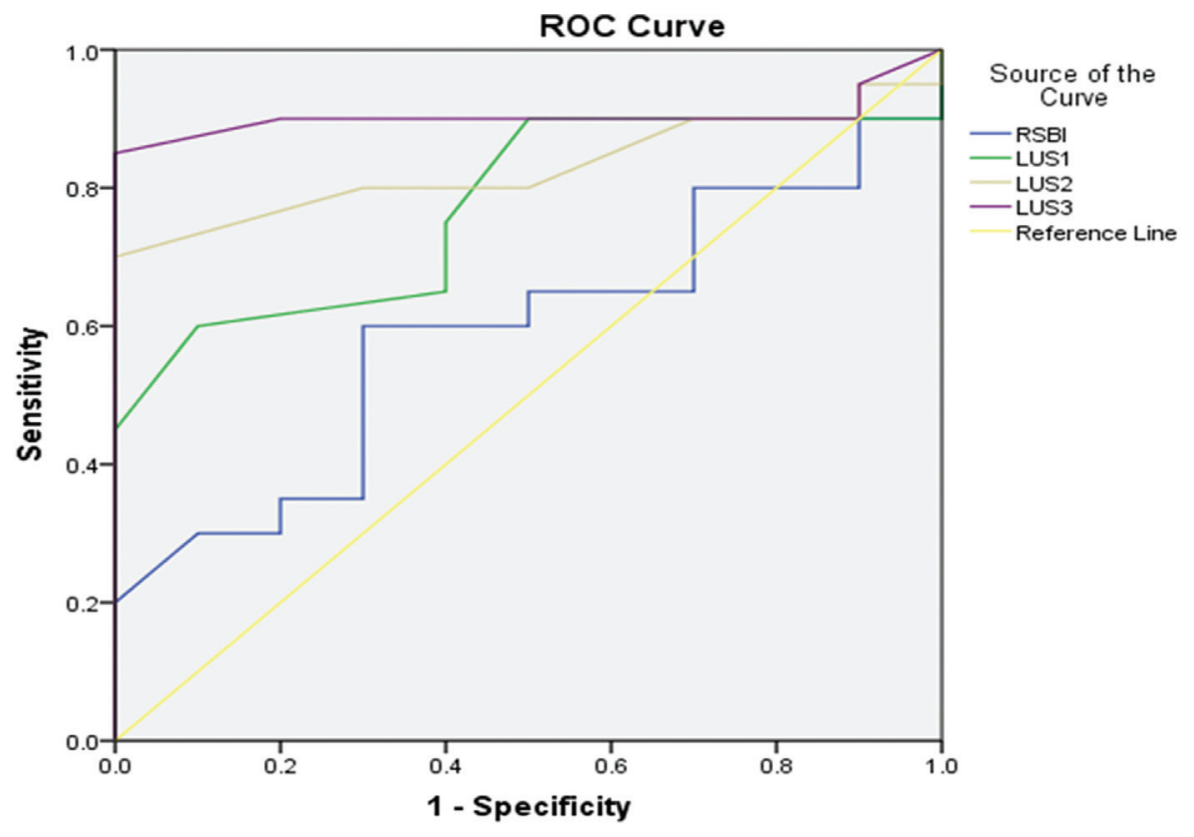

ROC curve analysis.

of RSBI in the failed group versus that of the successful group. In the contrary, Osman and Hashim [15] found that RSBI was higher in the failure than the success group, with median values of 113.9 and 71.9, respectively, which was considered statistically significant.

A statistically significant difference was found between mean LUS1, LUS2, and LUS3 for patients who failed to be weaned and that for who were successfully weaned. In the same context, Shoaeir et al. [18] performed lung ultrasound for all patients before weaning, during SBT, and $6 \mathrm{~h}$ after extubation. LUS score was higher in the failed weaning group than the successful weaning one, with $P$ value less than 0.001 [3]. Similarly, Haji et al. [17] found that LUS in the anterior and lateral chest wall regions was significantly different between successful and failed group, with median values of 11 and 17, respectively, with $P$ value of 0.007 . Moreover, it showed a lower significant statistical analysis when comparing the total score by adding the posterior wall score, with the result of weaning with median values of 22 and 18 for the successful and failed groups, respectively, with $P$ value of 0.06 .

Moreover, Soummer et al. [19] proved that LUS before SBT trial was 6-13 in the successful group and 13-17 in the failure group, with $P$ value less than 0.001. At the end of SBT, failed weaning group showed LUS 16-21, which is extremely higher than the successful group, 7-13, with $P$ value less than 0.001 . Following $4-6 \mathrm{~h}$ after extubation, failed weaning group showed significant derecruitement in lung aeration, with LUS ranging from 17 to 23 , against the successful group, with LUS ranging from 7 to 15 , with $P$ value less than 0.001 .

Similar to this work, Banerjee and Mehrotra [20] found a significant relation between weaning results and LUS, with mean values of $7.23 \pm 3.69$ and 20.77 \pm 5.79 for successful and failed groups, with $P$ value less than 0.0001 .

In this study, there was a statistically significant difference in the duration of mechanical ventilation between patients who failed the weaning process and those who were successfully weaned from mechanical ventilation. Similarly, Shoaeir et al. [18] found a significant relation between days on mechanical ventilation and weaning results, with $P$ value less than 0.001 . Moreover, Banerjee and Mehrotra [20] found that duration of mechanical ventilation was higher in failed group, with $P$ value less than 0.0001 .

This study showed a significant difference in the length of ICU stay between failed and succeeded weaning groups of patients. In the same context, Shoaeir et al. [18] found that the length of stay in ICU was significantly higher in the failed group, with $P$ value less than 0.001. Similarly, Tenza-Lozano et al. [16] showed with statistically significant values that failed weaning group of patients had a higher duration of 
ICU stay than successfully weaned group, with $P$ value less than 0.002 .

This study showed a significant linear correlation between LUS2 and length of ICU stay, with $P$ value of 0.048. In this context, Tierney et al. [21] found that higher LUS was positively associated with increased length of ICU stay $(P=0.003)$.

ROC curve was plotted to test RSBI, LUS1, LUS2, and LUS3 as predictors of weaning, and results were concomitant with the results of Soummer et al. [19] who found that LUS at the end of SBT more than 17 was highly specific for predicting postextubation distress with $\mathrm{AUC}=0.86$, and a LUS score up to 12 was highly sensitive for excluding postextubation distress. Moreover, Osman and Hashim [15] found that SBT-LUS less than 12 has high probability for success, 12-17 for intermediate probability for success, and more than 17 for high probability for failure. In another way, Tenza et al. [16] found that the optimal cutoff point for successful weaning was 7 , with sensitivity $76 \%$ and specificity $73 \%(\mathrm{AUC}=0.80)$.

\section{Conclusion}

Lung ultrasonography is a useful method in assessment of the degree of lung aeration during positive pressure ventilation, during and after SBT. So, it can be used as a good predictor of the weaning results. The best predictive measurement for LUS is at $4-6 \mathrm{~h}$ after a successful weaning trial. Early prediction of weaning failure by LUS can be helpful to prevent re-intubation by early initiation of NIV before actual failure.

\section{Acknowledgements}

This study was supported by Beni-Suef University Hospital.

\section{Financial support and sponsorship Nil.}

\section{Conflicts of interest}

There are no conflicts of interest.

\section{References}

1 Soni N, Williams P. Positive pressure ventilation: what is the real cost? Br J Anaesth 2008; 101:446-457.

2 Epstein SK, Ciubotaru RL, Wong JB. Effect of failed extubation on the outcome of mechanical ventilation. Chest 1997; 112:186-192.

3 Brochard L, Rauss A, Benito S, Conti G, Mancebo J, Rekik N, et al. Comparison of three methods of gradual withdrawal from ventilatory support during weaning from mechanical ventilation. Am J Respir Crit Care Med 1994; 150:896-903.

4 Rothaar RC, Epstein SK. Extubation failure: magnitude of the problem, impact on outcomes, and prevention. Curr Opin Crit Care 2003; 9:59-66.

5 Tobin MJ. Principles and practice of mechanical ventilation. Shock 2006; 26:426.

6 Heunks LM, van der Hoeven JG. Clinical review: The ABC of weaning failure - a structured approach. Crit Care 2010; 14:245.

7 Ferrer M, Valencia M, Nicolas JM, Bernadich O, Badia JR, Torres A. Early noninvasive ventilation averts extubation failure in patients at risk: a randomized trial. Am J Respir Crit Care Med 2006; 173:164-170.

8 Teixeira C, Maccari JG, Vieira SRR, Oliveira RP, Savi A, Machado ASA, et al. Impact of a mechanical ventilation weaning protocol on the extubation failure rate in difficult-to-wean patients. J Bras Pneumol 2012; 38:364-371.

9 Arbelot C, Ferrari F, Bouhemad B, Rouby JJ. Lung ultrasound in acute respiratory distress syndrome and acute lung injury. Curr Opin Crit Care 2008; 14:70-74.

10 Bouhemad B, Zhang M, Lu Q, Rouby JJ. Clinical review: bedside lung ultrasound in critical care practice. Crit Care 2007; 11:205

11 Soldati G, Sher S. Bedside lung ultrasound in critical care practice. Minerva Anestesiol 2009; 75:509.

12 Boles JM, Bion J, Connors A, Herridge M, Marsh B, Melot C, et al. Weaning from mechanical ventilation. Eur Respir J 2007; 29:1033-1056.

13 Putensen C, Theuerkauf N, Zinserling J, Wrigge H, Pelosi P. Metaanalysis: ventilation strategies and outcomes of the acute respiratory distress syndrome and acute lung injury. Ann Intern Med 2009; 151:566-576.

14 Koraaa EEDAW, Alya TM, Husseinb HS, Besharac SK. The role of chest ultrasound in detection of pulmonary congestion in hemodialysis patients. Egypt J Bronchol 2018; 12:482-485.

15 Osman AM, Hashim RM. Diaphragmatic and lung ultrasound application as new predictive indices for the weaning process in ICU patients. Egypt $J$ Radiol Nucl Med 2017; 48:61-66.

16 Tenza-Lozano E, Llamas-Alvarez A, Jaimez-Navarro E, FernándezSánchez J. Lung and diaphragm ultrasound as predictors of success in weaning from mechanical ventilation. Crit Ultrasound J 2018; 10:12.

17 Haji K, Haji D, Canty DJ, Royse AG, Green C, Royse CF. The impact of heart, lung and diaphragmatic ultrasound on prediction of failed extubation from mechanical ventilation in critically ill patients: a prospective observational pilot study. Crit Ultrasound J 2018; 10:13.

18 Shoaeir M, Noeam K, Mahrous A, Alaa A. Lung aeration loss as a predictor of reintubation using lung ultrasound in mechanically ventilated patients. Biolife 2016; 4:514-520.

19 Soummer A, Perbet S, Brisson H, Arbelot C, Constantin JM, Lu Q, et al. Ultrasound assessment of lung aeration loss during a successful weaning trial predicts postextubation distress. Crit Care Med 2012; 40:2064-2072.

20 Banerjee A, Mehrotra G. Comparison of lung ultrasound-based weaning indices with rapid shallow breathing index: Are they helpful? Indian J Crit Care Med 2018; 22:435-440.

21 Tierney DM, Boland LL, Overgaard JD, Huelster JS, Jorgenson A, Normington JP, et al. Pulmonary ultrasound scoring system for intubated critically ill patients and its association with clinical metrics and mortality: a prospective cohort study. J Clin Ultrasound 2018; 46:14-22. 